\title{
Study on the Application of Fine Management in Telecom Enterprise
}

\section{Zhenxing $\mathrm{Ge}^{1, \mathrm{a}}$ and Ying $\mathrm{Hu}^{2, \mathrm{~b}}$}

${ }^{1}$ College of Technology and Art Jingdezhen Ceramic Institute, Jingdezhen333000, Jiangxi Province, China

${ }^{2}$ College of Technology and Art Jingdezhen Ceramic Institute, Jingdezhen333000, Jiangxi Province, China

a181795184@qq.com, bhuhujdz@163.com

Keywords: Telecom Enterprises; Fine Management; Application

\begin{abstract}
Nowadays, fine management has gradually become an important methods to enhance the competitiveness of enterprises. Fine management uses relevant theories and technical means of modern scientific management to optimize the operating mechanism of modern telecom enterprises. Its emergence is of great importance to the management of telecom enterprise. This paper explores the specific content of the fine management of telecom enterprises, analyzes the problems existing in the detailed application of the fine management in the telecom enterprises, and puts forward some improvement measures. It is hoped that by promoting meticulous management, we can lay a solid foundation for deepening the reform of telecom enterprises and establishing the operation mechanism of modern telecommunications enterprises.
\end{abstract}

\section{Introduction}

As a new scientific management mode of modern enterprises, fine management is a combination of various indexes of program, pattern and data. It pays great attention to the requirements of detail, exerts the maximum utility by using limited resources, and helps the efficient operation of the whole enterprise. Facing with the fierce competition in the domestic market, violent impact of foreign related industries and the continuous refinement of market division, telecom enterprises introduce fine management to improve enterprise value, and strengthen the management and control of daily operation. It will undoubtedly help to control the cost of enterprises under the model of micro profit and achieve the continuous growth of the competitiveness of enterprise.

\section{The Content of Fine Management of Telecom Enterprises.}

Fine Planning Management. The plan is the detailed rules and procedures of planning ahead designed to achieve a certain goal. Fine planning management of telecom enterprises includes three main steps:

First, establish a scientific and reasonable target system. It is necessary to unify the implementation goals and plans, reduce the possibility and loss of plan failure; make the relevant capital of the enterprise combine with daily revenue and expenditure to distribute rationally to all departments, so as to avoid insufficient resources or waste. The whole goal of the enterprise should be decomposed to the small goals of the next level, put into the corresponding department from the superior to the lower level, and finally to the individuals.

Second, control the target. The superiors should give corresponding powers when they set goals and tasks with their subordinates. Before authorization, we should clarify the responsibilities and powers according to the different levels of different departments, so as to achieve the corresponding relationship between them.

Third, the implementation of effective incentives. Encourage the staff to participate in the goal setting. The leader assigns the task in a soft way, transfers the mandatory order of the staff to the appropriate fund support or reward, so that the employee's work autonomy is improved and the task is completed smoothly. 
Fine Talent Management. Market economy in China is changing rapidly, and telecom enterprises are constantly upgrading. The three major telecom operators hope to occupy the largest market. Management of talents has become a crucial factor for enterprises to gain competitive advantages.

First of all, we must improve the proportion of $5 \mathrm{G}$ network technology talents. $4 \mathrm{G}$ technology has been widely used, the research and application of $5 \mathrm{G}$ will be the direction of technology development of telecom enterprises in the next few years.

Secondly, increase the research talents who are good at marketing, planning and transaction management. If telecom companies want to win customers' favor in fierce competition, they must have a thorough understanding of the current market and have an efficient way of operation. Therefore, talents who understand the market are undoubtedly welcomed by all these companies.

Thirdly, establish a humanized salary system to fully stimulate the working enthusiasm of all employees. According to the ability of employees, we can divide their salaries, enhance their enthusiasm for work, reduce the loss of talents, and exchange small amounts of funds for greater economic benefits.

Fine Financial Management. The fine financial management is to apply the financial concept to the accounting measurement of every department and every economic business in accordance with the fixed methods and procedures, and to give full play to its special value and create great economic benefits for the enterprise.

First of all, aim at controlling costs and increasing revenue, the daily financial revenue and expenditure data of each project department of telecom enterprises should be measured and managed. For example, from the initial purchase of all products and materials, the daily production and management, the reasonable estimate of the value of the assets to the subsequent production and marketing and the cost of after-sales service, all should infiltrate into financial thinning, and always give full pay to the value. It is the necessary measure to reduce the risk of management.

Secondly, to do fine management means, that is, to implement the financial management resources in the daily operation, to ensure that the normal work of the enterprise management is constantly implemented, so that the complex data become clearer, detailed and organized and many monotonous data become flexible and rich. The telecom enterprises have a large number of data inflows every day, so professional technicians should be assigned to integrate all the data, analyze them thoroughly, eliminate unnecessary error data, retain useful related data, find out the law of development, and finally form the analysis report to provide an important reference value for telecom operators in future management.

Finally, pay attention to the efficiency and cost of implementation. Fine development is of course important, but if the telecom enterprises pay too much attention to the fine management of enterprises and ignore the most basic efficiency problems, a lot of human resources and material resources are wasted, it will cause an unexpected loss to the development of enterprises. This is not worth the loss.

Fine Quality Management. The implementation of fine quality management in telecom enterprises is to manage every department, every market management organization, and every staff member of the whole enterprise. This quality management model can improve the quality of every link in the production and operation of the enterprise, and more efficiently meet the needs of the customers.

First of all, it is necessary to formulate a strategic line for telecom enterprises. According to the actual situation of enterprises and departments, implement different strategic plans. Establish a partnership with suppliers, make quality requirements for the product according to the customer's needs, implement quality management training and education, construct standardized quality measurement index, and establish the cost of quality standards.

Secondly, promote the quality concept and strengthen the refinement measures. By carrying out the relevant exchange meetings or employing relevant experts to hold training courses, the quality concept of the employees will be strengthened, and the concept is fully penetrated into all aspects of the daily management of the enterprise. So the competitiveness can be improved and the huge profit 
for the development of the enterprise is created.

Thirdly, to build an effective quality system. The quality system refers to a series of elements that must be provided for the implementation of quality management, including the relevant processes for the quality management implementation, the staff members, and any property materials needed in the process of operation. If the enterprise needs to meet the required quality requirements in advance, it is necessary to simplify the complex quality program flow into a simple one and subdivide the relevant details.

\section{Problems in the Application of Fine Management in Telecom Enterprises.}

Lack of Clear Strategy of Technological Innovation. Telecom companies lack technological innovation and do not know how to plan ahead. Without standard management, the monotony of the overall operation of enterprises makes resources difficult to concentrate and there is no basis for the implementation of an innovative strategy. Each innovation entity has its own way of doing things. There are more duplicate projects in research and development, and the efficiency of enterprises research is not high. The shortage of innovative talents, the lack of enthusiasm for scientific and technological personnel to engage in innovative activities, and the backward evaluation mechanism of technological innovation results are the main bottlenecks that restrict the upgrading of technological innovation capability of telecom enterprises. Even if the relevant incentive mechanism was introduced, it was aborted because of the irregular system and unreasonable procedure. This makes some scientists and technicians unable to devote themselves to their work. Instead, they try their best to switch to management.

Not clear the focus. In our daily work, we must deal with a great deal of affairs. How to arrange, what to do and when to do should be classified and analyzed in combination with reality. How to deal with the daily operation of telecom enterprises is a problem that all leaders should solve. The decentralization of power by the leaders of the telecom enterprises should be treated with a special perspective. They should not pay too much attention to the control of power. It is necessary to understand the appropriate decentralization to the lower departments, and the left power should be analyzed in detail according to the actual situation.

Lack of Attention to Details. There are no lack of people who want to do great things, have lofty ideals, aspirations, and aspiring to perform their talents, but few people are willing and able to handle small tasks in their daily work, not to say that these small things are subdivided and repeated. Therefore, we must change the cognition of things, pay attention to the details, and deal with things diligently, conscientiously and responsibly. In a word, if the telecom enterprises want to occupy a place in the increasingly competitive society, we must pay attention to any details in the daily management of the enterprises, and do not cause the economic loss of the enterprises because of some mistakes.

Lack of A Sense of Crisis. For an enterprise, whether there is a relevant sense of crisis is sometimes a decisive factor for success. Many large enterprises in developed countries pay great attention to the cultivation of employees' crisis awareness, so that all employees can attach importance to it. They usually invite experts and scholars from relevant fields to teach on the spot, so as to create a special ideological atmosphere. These are the lack in China telecom enterprises. Once all kinds of accidents happen, it will be too late to take action and maybe there is a huge economic loss at last.

\section{The Improvement Measures}

Perfect Mechanism to Motivate Technological Innovation Talents. Compared with other enterprises, the industrial process cycle of high-tech related enterprises is very long, the requirements for related innovative talents are high, and the expected income of the economy is difficult to determine. The input of innovative talents is so important to these enterprises. Therefore, the telecom enterprises should pay great importance to the training of innovative talents, establish and improve the corresponding incentive mechanism, increase the investment of funds, increase the 
introduction of talents, prevent the loss of talents, and construct a proper evaluation system to assess the ability and value of the talents. The enterprise should open up a green channel for outstanding employees' salary opening level and job upgrading mechanism. The continuous growth of technological innovation talents will create huge economic benefits for enterprises.

Promote the Renewal of Ideas. In order to improve the management level of telecom enterprises, we should carry out fine management scientifically and penetrate into every practice link, and do well in coordination which based on the scientific management and control system. Relevant departments of the state should delegate some functions and powers to the telecommunication enterprises, guarantee the specific implementation of their plans, and make the management and control of funds, property and materials more convenient. The planning of variou s departments can be formulated in combination with the actual conditions, so as to ensure that the management can fully penetrate all aspects of the daily production and management activities of the telecom enterprises and promote the development of the enterprises.

Managers Should Do Their Best to Carry Out Fine Management. Due to various reasons, there are more or less these problems in China's telecom enterprises, such as: employees are not motivated and lack of initiative, management layers open stock conditions and continue to issue shares in order to take possession of the rights and interests of the company, and financial data is fabricated that violates the relevant accounting regulations, etc. Therefore, relevant supervisory system should be established in advance to reduce fraud. Enterprises should embark on formal development channels and upgrade their technological innovation and daily management performance. In the process of implementation, it is necessary to strengthen the management and control of the relevant managers of the enterprise, carefully handle the relationship between departments and staffs, so that all the staff can play their value.

Pay Attention to the Cultivation of the Fine Concept and Consciousness of the Staff. Thought plays an important guiding role in behavior. It is necessary to cultivate meticulous ideas, which is of great significance for the future development of enterprises. But at present, this concept is not long enough for most people to understand. And in China's telecom enterprises, the acceptance of this concept is mainly concentrated in the leadership of the higher level, and the majority of the employees in the lower class are less affected. Enterprises should carry out relevant meetings to train staff, pay attention to the strengthening of the awareness of staff, which not only improve the quality of staff, but also help to create a unique atmosphere of business work.

\section{References}

[1] Wang Yu. Study on the Implementation Path of China's Fine Management Mode. Management Observation, 2014.

[2] Zhong Dahai. Focus on cultivating fine management culture. Southern Forum, 2013.

[3] Cai Hongxuan. How to Implement Fine Financial Management in Enterprises -- Taking Telecom Industry as An Example. Finance and Accounting for International Commerce, 2014.

[4] Su Li. Strategy of Fine Marketing for Telecom Enterprises. Money China, 2014.

[5] Yang Ruimei. Construction of Fine Management System Based on Competitive Advantage. Enterprise Reform and Management, 2013.

[6] Peng L, Fang W. Heterogeneity of Inferring Reputation of Cooperative Behaviors for the Prisoners' Dilemma Game [J]. Physica A: Statistical Mechanics and its Applications, 2015, 433: 367-378. 